with an ill-defined swelling in the cacal region, and operation was advised. On admission on Jan. 30th the patient was in very fair condition, and the tumour was much less distinct. The pain and tenderness had also disappeared. The abdomen was opened on Feb. 1st, and after adhesions had been separated the swollen appendix was discovered behind the cxcum, harder and firmer than usual. It was ligatured at its base and removed, the peritoneal covering being sutured separately over it. On laying it open after removal, muco-pus escaped, and the mucous membrane was found thickened and congested. The lumen was much diminished at its cæcal extremity, but a small probe could be passed. No drainage was employed, and the layers of the abdominal wall were sutured septrately. The patient made an uninterrupted revovery aud left the hospital on Feb. 24th looking very well.

CAS3 8.- A man aged thirty, a patient of Mr. Lambert of Farsley, was seen by me in January, 1894, recovering from an attack of inflammation in the cæcal region; a tumour about the size of a small pear could be felt, and there was marked tenderness. He had had six similar attacks during the two previous years, and in each seizure his medical attendant had been able to feel the tumour. The attacks had been increasing in severity, and the last had kept him in bed a fortnight. On admission on Feb. 5th, a month after the last seizure, he was in fair general health, and no lump could be felt, although there was some tenderness at McBurney's point. On the 15th, when the abdomen was opened, there was great difficulty in finding the appendix, on account of extensive and firm intestinal adhesions in the crcal region. It was at last found buried in a thick layer of old adhesions behind the cæcum. When separated it was found to be small and doubled back on itself. After removal a stricture was discovered at its cæcal extremity, which only admitted the very finest probe. The distal end was dilated and contained a little yellowish clear mucus. Its coats were thickened, and the mucous membrane was congested. No drainage was employed. The wound healed by first intention, and recovery was uninterrupted. The patient is now at his work and has had no return of pain.

CASE 9.--A married woman aged twenty-five was sent to me by Dr. Howell of Middlesbro' with the history of having been ill more or less for seven years, during which period she had suffered frequently from attacks of pain in the abdomen. Her most severe seizure had occurred five months previously, and she said this had started just as her previous attacks had done, but on this occasion Dr. Howell discovered a swelling in the region of the cæcum. She was in bed nine weeks, but soon after getting about again another attack occurred, and the tumour was again perceptible. Her general health had failed seriously, and she was very thin and ill-looking. When we saw her together there was a decided fulness and tenderness over the cæcum, McBurney's point being well marked. Recurrent appendicitis was diagnosed, and the patient was operated upon on Feb. 22nd, Dr. Howell assisting me. Namerous adhesions were discovered, and with difficulty a diseased appendix was removed from behind the cæcum. The wound healed by first intention, and although the patient developed a small patch of pneumonia within a week of the operation-apparently dependent on a chill received on the journey to Leeds-she made a good recovery and was able to return home within the month.

I have operated on other cases where recurrent appendicitis has gone on to perforation or abscess, but I prefer to limit my remarks to the characteristic ones related, where the operation was performed between the attacks. In such cases there are clearly three courses which may be pursued :1. Non-operative, trusting to rest and diet, with opium if required, in order to bring about resolution in the hope that the existing attack may be the last. 2. Operation on the second or tnird day of a seizure as advised by Dr. F. S. Dennis and other American surgeons who discourage the removal of the appendix between the attacks on the chance that there may be no recurrence. 3 . Operation in the quiescent period, between the attacks. My practice will show that I decidedly prefer to operate in the quiescent period if opportunity be given to choose the time - (1) because the patient is likely to be in the best possible condition; (2) because there is less likelihood of there being an extensive collection of inflammatory products in or in the neighbourhood of the appendix. and therefore there will be less danger of soiling the general peritoneal cavity and less fear of peritonitis ; (3) an operation in the quiescent period seldom requires drainage, and therefore the wound can be made secure, and there will be less likelihood of hernia following operation; and (4) the appendix can be dealt with in a more satisfactory manner than when it is acutely inflamed and hidden by greatly distended intestines. In deciding on the line of treatment, $q u \hat{a}$ medical or surgical, the patient should have matters fully explained to him, the dangers of recurring attacks, with the sufferings and inconveniences, being balanced against the risk of operative interference and the result, gained by operation; therefore, in all these cases I would urge the coöperation of physician and surgeon, so that, if possible, the opinion given may be free from bias. Can these several risks be estimated? Fitz gives the mortality of perityphlitis medically treated as 11 per cent.; this is probably too high for attacks of recurrent appendicitis, but who is to say that in any case the next seizure may not end in perforation and death? What are the inconveniences? In all the cases related, incapacity for the ordinary pursuits of life and practically chronic invalidism were marked features. What is the likelihood of recurrence? In the cases related there seemed to be every probability of the recurrences being repeated indefinitely, and I should say that if in any case the attacks were repeated two or three times they would not unlikely recur many more times until some complication supervened.

What are the risks of operation in the quiescent period? Here we stand on more certain ground, for published statistics prove the dangers to be very slight in the hands of those accustomed to such operations-I -I believe not more than 2 or 3 per cent. And, lastly, What are the results which may be looked forward to after recovery from operation? In such cases as have been reported, and in my own now mentioned, the patients have been apparently completely cured.

Although I do not agree with those surgeons who argue that every case of appendicitis should be operated on, I do feel that in recurrent appendicitis operation shonld be resorted to as soon as it becomes evident that there is a probability of the attack being repeated, especially as the operation is one that can be undertaken in the quiescent period with every prospect of immediate and ultimate success.

For the notes of Cases 5, 6, 7, and $8 \mathrm{I}$ have to thank my house surgeon, Mr. C. H. Oldfield.

Leeds.

\section{NOTE ON DIARRHEA AND ITS RELATION TO FRUIT AND THE FEEDING BOTTLE. ${ }^{1}$}

By J. SPOTTISWOODE CAMERON, M.D., B.Sc. EdiN., CONSULTING PHYSICIAN TO THE HUDDERSYIELD INFIRMARY, MEDICAL OFFICER OF HEALTH FOR LEEDS, ETC.

LAST autumn the annual death - rate from autumnal diarrhœa was 3.5 per 1000 in the 33 great towns, 3.8 in 50 large town districts, and in England and Wales (less these 83 towns) 2:1. Last autumn was, however, a period of unusually high mortality from this cause. The diarrhoal death-rate had been 40 per cent. above the autumn average of the ten preceding years in the 33 towns, 123 per cent. above in the 50 town districts, and 110 per cent. in the rest of England and Wales. Many districts, especially in Lancashire and Yorkshire, with a usually high rate from this cause, had a smaller proportionate increase last autumn than others with an ordinarily lower rate. Thus, amongst the large towns Leeds, with a decade rate of 3.4 , ran up 50 per cent., to $5 \cdot 1$; while Bradford, with a decade record of $2 \cdot 1$, rose 105 per cent. to reach $4 \cdot 3$. Hull, however, with the high decade rate of 3.0 per 1000, proved one of the exceptions to this rule, as its rate rose last autumn to 8.4 , or 180 per cent. The question naturally arises, Had the cheapness of fruit anything to do with this increase? Hull largely imports and Leeds largely consumes fruit. Has the habitually high diarrhœa-rate in Leeds, increased last year by 50 per cent., and has the habitually high rate at Hull, increased last year by 180 per cent.. anything, or any great thing, to do with fruit? Speaking offhand, one is inclined to answer "No." The mortality from diarrhoea, as every medical man knows, is chiefly amongst young infants, who do not generally get much fruit. Still, it might be answered that if they do not

A paper real before the Yorkshire Branch of the British Medical Association, at Leeds, May 30th, 1804 . 
their motiers do, and "hence these tears." To assist in getting a the facts a series of questions were issued last autumn $t$ the ward inspectors in Leeds who were examining the drainge and general house conditions where death had occurred from diarrhoea. In addition to the ordinary information sought as to drain disconnection, neighbouring nuisancis and the like, they were asked to inquire whether the patint (or, if an infant, its mother) used any uncooked fruit, ard to find out the condition of any such fruit as to ripeness and the date when it was taken. In the case of infant further inquiry was made as to the diet of the patien and the mode of cleansing the feeding bottle. These additinal inquiries were made as to all deaths from diarrhoea registred after Aug. 19th, but as the disease ceased to be epidenic at the end of September I do not deal here with any lut the deaths registered in the last six weeks of the antunn quarter. Altogether in the fourteen weeks ended Sept 30th, and which are the weeks in which the disesse was specially prevalent in Leeds, 520 deaths from diarhoe ${ }^{2}$ were registered in the city, 468 (or 90 per cent.) of then amongst children under two years of age. During the last six weeks of this period the total diarrhcea deaths regstered were 216, amongst which were 187 of infants under twc. The six weeks may therefore be regarded both as to nunbers and age as fairly representative of the autumnal epilemic. As to three of the fatal cases we could not obiain the information sought. The remaining 213 deaths thas specially inquired into comprised 20 of persons over three, of whom 16 were also over fifty-five. Of the 193 children under three, 58 were partly or entirely at the breast, and the remaining 135 were not at the breast at all.

of the 58 deaths amongst children more or less dependent opon their mothers for nutriment we learned that none had any uncooked fruit given to them. In six cases out of the 58 it was stated, however, that the mother had herself eaten incooked fruit during the time she was suckling the child. As to two other of these 58 fatal cases we were told that the mother of one had eaten boiled apples and the other cooked cauliflower somewhat freely. Even adding these to the 6 , we have still only 8 ont of the 58 in which fruit might be regarded as connected with her child's illness. In the case of the remaining 50 we were distinctly told that no uncooked fruit was taken by the mothers during lactation. As to the 135 infants under three not at the breast at all it might not be considered necessary to ask any further question about the diet of the parent, but, as some might have been recently weaned, we did ask in every case if the mother had herself partaken of fruit while nursing the child. In every case the answer was "No." In regard to the children themselves, two of them, both in the second year of life, were said to have eaten fruit. One, a girl of seventeen months, is said to have consumed about one uncooked apple a day ; the other, a boy of thirteen months, teething, was allowed to chew at a raw apple, and as he seemed to have a desire for something of the kind they cooked him one and let him eat it. Two, therefore, of the 135 children under three not at the breast whose deaths were inquired into ate fruit. The remaining 133 are distinctly stated not to have had any.

There remain the 20 deaths at maturer years. Of these patients the yourgest was aged six, 19 were over thirty-five, of whom 14 were more than fifty-five, and 8 of these were more than sixty-five. Amongst the latter a man of sixty-six, who had had an apoplectic seizure two years previously, is said to have eaten a great quantity of moderately ripe plums and some roast apple. A woman of forty ate a few apples and plums from Nottinghamshire. Two of her children, aged fourteen years and one year respectively, also suffered from diarrhœa, but recovered. In the other 18 fatal cases it is said that no fruit in an uncooked state was partaken of. These numbers, of course, are small; they deal only with 213 deaths occurring, however, while the epidemic was still unabated. Of these, in regard to 201 (or more than 94 per cent.) the statement was distinctly made to our inspectors in answer to express inquiries that no fruit had been partaken of by the patient, or, if the patient were an infant, by the mother while it was still at the breast. On the whole, so far as these returns go, they would seem to show that, at least in Leeds, fruit played a less important part in raising our diarrhcea mortality last autumn than is sometimes supposed.

A word or two about the feeding bottle. The 213 deaths

${ }^{2}$ Excluding, as the Registrar-General does, deaths certifled as English cholera or cholera, but including deaths from "choleraic diarrhoea." registered in the last six weeks of the quarter, and specially inquired into as above, included 153 amongst infants under one year, somewhat short of six-fourteenths of the 397 at that age whose deaths were registered in the fourteen weeks. Dividing these young infants into four age groups according as their death occurred in the first, second, third, or fourth trimester of life, each group was practically the same percentage of the 153 as the corresponding groups in the fourteen weeks were of the 397. so that the deaths at this age investigated are fairly typical in this respect of those of the epidemic. Dividing all the 153 according as they were fed entirely at the breast or not, we find that 18 per cent. of these infants under one year who died of diarrhcea had been fed entirely at thejr mothers' expense. The percentage varied, as might be expected, in the different three monthly age groups. It was 25 per cent. in those under three months; 16 per cent. in those between three and six months; and 3 per cent.in those between six and nine months. Somewhat unexpectedly the percentage rose to 29 in the age period ketween nine and twelve months. Fonrteen per cent. of all the infants under one year, whose deaths were investigated bad been partly but not entirely at the breast. At the three monthly periods these formed (in their order) 20 , 13,9 , and 17 per cent. Seventy-six per cent. of the 153 were wholly or partly fed by the bottle. Nearly 12 out of the 76 per cent. were partly at the breast. These bottle-fed babies formed 70 per cent. of the infants who died under three months of age (including $17 \frac{1}{2}$ per cent. partly breast fed). At the successive age periods the percentages were $76 \frac{1}{2}$ (including nearly 11 also at the breast), 91 (including 9 partly breast-fed), and at the period of nine to twelve months 62 (including 8 per cent. also indebted to the mother). Altogether, of the 213 deaths inquired into, 129 were those of infants fed wholly or partly by means of the bottle, 109 of them entirely artificially, and, of these 109, 98 were under one year at the time of death. All the 129 were under two years of age. In 86 of these 129 , or 66.6 per cent., we were told the feeding bottle was scalded; in the remaining 33.3 per cent. that it was not. Washing soda, soap, borax, tea Jeaves, and washing powder are variously stated to have been nsed as detergents. The use of a brush was pretty constant. Out of the 43 cases where the bottle was not scalded a brash was employed in 25 . Of the 86 cases where the bottle is said to have been scalded, in 37 the brush was used. While in the former, the not scalded class, it almost goes without saying that the brush also remained unsterilised, it is to be feared that in many cases where the bottle itself may have had a wash out with boiling water the brush may have remained in its unsterilised condition. The tube, too-the asual accompaniment of the feeding bottle-is still more difficult to sterilise. While, therefore, a third of the feeding bottles used were admittedly unsterilised, it is to be feared that the contents of a still larger proportion were exposed to infection from brushes and tubes not rendered aseptic. Beyond this is the difficulty as to the vessel in which the milk was stored and the place where it was kept.

Of the 605 fatal cases of diarrhoea in Leeds in 1893, 66 per cent. occurred in houses either without drains or with drains not properly severed from the sewer, and one-fifth of the remainder (making 73 per cent.) had other sanitary defects. In my opinion it is to the feeding bottle and to the infection of its contents rather than to fruit that attention must be most especially directed in the prevention of aatumnal diarrhœa. Milk to be used for infants should in warm weather be kept out of the reach of effluvia from diains, traps, middens and dustbins. It should be sterilised as soon as it arrives in a clean bottle, which should be kept stoppered till it is needed. The water added to the milk should have befn boiled. The feeding bottle should be cleansed every time it is used and scalded immediately before it is used again. It should have no tube.

Leeds.

Presentations.-At a meeting of the St. John Ambulance Association, Wooburn Green, on June 6th last, Sir Herbert Perrot in the chair, Mr. W. G. Weaver, the lecturer, was presented with the gold medal of the order and a handsome pocket-book, the former by the ladies of the class and the latter by the men.-Mr. Robert Simpson of Bristol has been presented with a fountain pen and pencil, and also a handsome dinner-gong, in recognition of his services as lecturer to the St. John Ambulance classes in connexion with the King-street Wesleyan Chapel. 
REST, PHYSIOLOGICAL AND THERAPEUTICAL, IN THE TREATMENT OF
EYE DISEASES.

Bx H. MACNAUGHTON-JONES, M.D., M.A.O., M.CH., F.R.C.S. IREL. \& EDIN.

I NEED not insist on the vital importance of securing physiological rest in ocular therapy or on the pernicious effects which frequently ensue on various forms of unrestful treatment as well as from neglect of those necessary restful measures that in themselves bring about subsidence of inflammatory processes and relief of pain. The avenues through which reflex irritations may reach the eye are many, and the sensitiveness of the organ is shown, not only to direct stimuli when applied to it externally, but also to those physiological impressions which reach it from different directions, and which, not being apparent, are more likely to be overlooked. They prove that behind the various probable or possible sources of ocular irritation which we regard as local there are others which have to be sought for and treated before we can secure entire physiological rest to the eje. Referring to ocular reflexes, I may briefly summarise the various nervous and vascular correlations that influence the condition of physiological equilibrium in the globe of the eye. Such a summary (illustrated by the scheme ${ }^{2}$ shown) of possible nervous excitations embraces the many complex channels of reflex communication and irritation between the cranial nerves and the sympathetic distribution, more especially betwixt the second, third, and fifth nerves. I necessarily include the connexions between the cerebral centres - the nuclei of origin of these nerves and the spinal cord-with their peripheral links of communication. This anatomico-physiological review throws a light on many ocular reflected inritations, more particularly those arising from the loop of communication of the fifth nerve and its ophthalmic division. More intimately bearing on the normal equilibration of the intra-ocular fluids and the circulation in the ocalar tunics is the part played in preserving the normal tension (through the ciliary zone) by the filtrating media in the iritic angle. Clinical examples of this fact we are familiar with in glaucoma, traumatisms, and ulcers in its neighbourhood. I would cite as further examples of these reflected states of unrest the oculo-motor and retinal affections which attend upon cervical and mediastinal growths, on degenerations, tumours, and traumatisms of the spinal cord. We see this distant source of irritation exemplified in the ocular troubles that follow upon the affections of the uterus, carious teeth, nasal diseases, the use of the galvano-cautery in the nose, and disease in the mastoid antrum. I may instance contrariwise the unpleasant consequences we have to treat as complications of astigmatism in headache, nausea, migraine, and the intercurrent neuralgias of the eye, ear, and nose which are met with in these cases of errors of refraction. In his philosophical work on "Rest and Pain" Hilton compares the eye in its superficial coverings and its nerve supplies, sensory and motor, with the synovial membrane of a joint, its muscular structures and nerve supply. And he goes on to say, after having drawn attention to the close connexion existing between the facial, or motor, and the fifth and sensory nerves: "Now notice what happens when the eye is inflamed or the ligbt is too strong for the eye. ..... The eyelids are immediately closed ...... the eye is placed in darkness, which is the eye's 'rest.' Here is an indication on the part of nature which has been visible to mankind from one generation to another, and soliciting, as it were, attention ; yet how little is it appreciated, how rarely made the guide of practice? Surely the neglect of such an indication is a great error and requires correction. If the eye be inflamed (painful, irritated, red, congested, very sensitive) by exposure to a strong, glaring light or to intense heat, immediately the eyelids are instinctively closed, thus adopting the principle of rest as a means of restoration, tears are secreted, analogous to synovial secretions in joint inflammations, to lubricate the conjunctival membrane, to interpose a layer of fluid between the globe and the eyelids, to prevent direct

a Abridgment of a paper real before the West London MedicoChirurgical Society on May $4 \mathrm{tb}, 1804$.

had necessarily to be omitted, this portion of the communication being in abstract. friction of the two mucous surfaces, and possibly to foment the eye. If the eye be thus kept in temporary larkness, free from friction, and thus rested, it will return in a few hours to its normal state without any other aid.'

There is another organ which, in its exquisitely sensivive and highly vascular structures and the nervous influence transmitted to it by reflection, is, from a clinical and therajentical point of view, somewhat analogous to the eye--I refe: to the testicle. Many years ago Mr. Furneanx Jordan, in dawing attention to the value of combining the three princplesrest, counter.irritation, and pressure -in the treatment of inflamed parts, specially instanced acute orchitis as an example. This was but one of many instances in which he advcated counter-irritation applied over the adjacent vascular teritory to the part affected. The treatment he then adrocaed I have ever since pursued, without in a single instance faling to rapidly effect a cure. It consists of the application of a strong iodine pigment in the course of the femoral arery applied over Scarpa's triangle. A solution of nitrate of siver (one drachm to the ounce) is painted over the scrotum on ihe side of the affected testicle, rest and pressure being secured by the suspension of the testicle in a light poultice of linse:d. Here derivation and counter-irritation result from the iodie, pressure and counter-irritation from the nitrate of silver, and pressure and rest from the saspensory poultice. In the case of the eye this tripartite therapeutical method of securing physiological rest is best exemplified by the well-known treatment which is so successfully adopted in certain cass of ulceration of the cornea and the various complications that follow or accompany suppurative corneitis-viz., th: application of a properly adjusted pressure bandage $0^{*}$ compress, and the use of a correctly inserted seton in the temple. The value of such therapeutical steps is further enhanced by paracentesis and the instillation of atropine or physostigmine, according as either of these alkaloids is specially indicated.

I may remark in passing that the tendency to the universal disuse of old methods of treatment in practice is much to be regretted, as depriving the practitioner of some of the most valuable therapeutical agents. The contempt of well-timed vesication of the skin of the temple, the use of an "occasional leech" in inflammation of the eye, are examples of such prejudices. Another instance of obtaining rest, akin to the foregoing, may be cited in the relief of blepharospasm by the careful painting of the pigment of iodine in circular form over the palpebræ, or by the formation of a slight eschar on the skin of the upper eyelid through the application of a pencil of solid nitrate of silver. In the same affection rest is obtained by the use of a compress bandage, to be followed, if necessary, by a division of the outer canthus. The careful discrimination demanded in the employment of two of the simplest, while at the same time most powerful, means of securing rest to the eye it is hardly necessary to touch on ; still, only those who have had large experience in the treatment of eye applications know how beneficial, on the one hand, or disastrous on the other, may be the consequences which follow upon the use of heat or cold in inflammations or traumatic conditions of the eye. The subjugation of pain and the sense of comfort experienced by the patient are nature's indications as to the continuance of warmth or cold, though even these are not always to be relied upon. This is most typically shown in inflammatory states and ulcerations of the cornea, where we have to steer between the encouragement of suppuration by heat or the retardation of repair by cold. The most serious consequences do, however, occasionally arise from the intermittent effects produced by cold compresses which are not frequently renewed, and for this reason irrigation by Leiter's tube is often the best means to secure a uniform temperature,

The ophthalmic ice-bag which is depicted below has been made for me by Messrs. Arnold and Sons. The idea is in part borrowed from the aural ice-bag of Sprague. The ice is retained in the bag, which is readily removed from the head band by means of a single clamp. It must be granted that the commonest of all causes of unrest to the eye, bringing in its train associated disturbances of function in the brain, superficial cranial nerves, and even in the stomach, is error of refraction. The neglect of an examination for refractive aberrations, especially in children and during adolescence, has brought about serious reflex disturbances, all of which have completely disappeared with the use of a mydriatic and the adjustment of suitable 